\title{
MECHANICAL BEHAVIOR OF HORIZONTAL SWIVEL SYSTEM WITH UHPC SPHERICAL HINGE UNDER SEISMIC ACTION
}

\author{
Jiawei Wang, Bing Cao, Bo Huang and Yihan Du
}

\author{
Anhui Polytechnic University, School of Architecture and Civil Engineering, Department \\ of Civil Engineering, Wuhu City, Beijing Middle Road, China;wjw526@126.com; \\ caobing.0427@163.com; huangbo@ahpu.edu.cn; duyihan00@163.com
}

\begin{abstract}
In the process of rotation, the total weight of the bridge structure is jointly supported by the spherical hinge and the supporting structure, and its lateral stability is poor. It is easy to lose stability under the action of dynamic loads such as seismic action effect. The present paper takes a 10,000ton continuous rigid frame swivel bridge as the re-search object, analyzes the dynamic response of the seismic action to the horizontal swivel system and establishes several structure simulation models. Eighteen seismic waves in three directions that meet the calculation requirements are screened for time history analysis and compared with the response spectrum method. Finally, an optimization algorithm for the seismic response of the bridge under horizontal swivel system is proposed based on the mode superposition method. The UHPC spherical hinge bears all the vertical forces and $20 \%$ of the bending moment caused by the seismic action, the support structure bearing the remaining $80 \%$ of the bending moment. The optimization algorithm proposed in this paper features high accuracy.
\end{abstract}

\section{KEYWORDS}

Horizontal rotation, UHPC spherical hinge, Rotating process simulation, Seismic time history analysis, Optimization algorithm

\section{INTRODUCTION}

It is known that applying conventional construction methods for continuous rigid frame bridges is not advisable when crossing railways. The full framing method requires a railway protection shed; thus, it will affect the normal operation of the railway. While the cantilever pouring method requires symmetrical construction in sections, and it features a long construction period. Besides, the application of large cantilever poses safety hazard to the operation of the train. Under these circumstances, the rotating construction method becomes the most advantageous method, which could reduce the impact of bridge construction on railway operations. First, complete the construction of the bridge superstructure and rotating piers on both sides of the railway. Then, the horizontal traction equipment on the cap is used to rotate the bridge swivel system composed of the superstructure, the swivel pier and the spherical hinge to a certain angle (usually $90^{\circ}$ ) along the central axis. When the superstructure of bridge crosses the railway line, it is connected with the side pier, finally completing the structural system conversion [1-4].

In the process of bridge rotation, the spherical hinge structure is the most important part of the bridge rotation process. The swivel bridge constructed during 1980-1990 mainly used concrete spherical hinges [5-8], as shown in Figure 1-1a. Concrete spherical hinge features low cost but also poor bearing capacity, and is therefore mainly used in small tonnage bridges. With the continuous increase in tonnage of the swivel bridge and the rapid development of the manufacturing industry, the prefabricated steel structure spherical hinge in the factory has gradually become the first choice for the spherical hinge, which has the advantages of high bearing capacity and good contact surface 


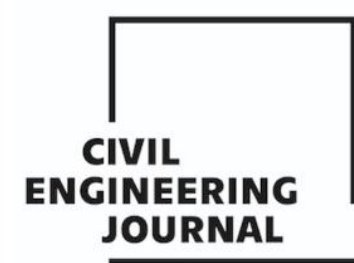

Article no. 35

THE CIVIL ENGINEERING JOURNAL 2-2021

flatness, as shown in Figure 1-1b. However, the cost of steel spherical hinges is relatively high. A 20,000-ton spherical hinge can even cost several thousand dollars. In order to solve the shortcomings of the traditional spherical hinge structure, this paper applies Ultra-High Performance Concrete (UHPC) material to the spherical hinge structure [9-12]. The size of the UHPC spherical hinge greatly reduces the radius of the concrete spherical hinge, and at the same time reduces the manufacturing cost of the UHPC spherical hinge, all bringing high economic benefits.

During the rotation process of the horizontal swivel system, the spherical hinge and the supporting structure jointly establish the support system. When subjected to dynamic loads such as earthquakes effects, the bridge is prone to instability during the vibration process. Changjie Wang and Wei Hei analyzed the seismic response of a T-shaped rigid-frame rotating bridge in the completed state, and calculated the bending moment envelope diagram of the main girder and piers of the superstructure under seismic action by the response spectrum method. It is found that the structure is always in an elastic state, and the load-bearing capacity of the structure meets the design requirements [13]. However, the research is limited to the analysis of the completed bridge state, i.e., the two ends of the main beam are simply supported, and the pier positions are consolidated. The seismic response analysis of the maximum cantilever state during the rotation process is not performed. The constraint in the maximum cantilever state is poor, the frequency of the first three modes is small, and the swivel system is more prone to instability under dynamic loads. Although seismic action is a combination of accidental effects, it is necessary to carry out seismic calculation and isolation design for important bridges in earthquake-prone areas or bridges with poor stiffness. So, the rotating bridge therefore must be subjected to seismic calculations in the maximum cantilever state (in the process of rotation) and the completed bridge state (rotation completed).

Based on a 10,000-tonnage continuous rigid frame UHPC spherical hinged translation system bridge, this paper introduces the calculation method of seismic time history analysis of the system in the maximum cantilever state (in the process of rotation) and the bridge state (in the process of rotation completed) and mainly analyzes the influence of UHPC spherical hinge and the footing structure on structural stability under seismic action, proposing an optimization algorithm for the seismic response of the translation system and several structural measures to improve the seismic performance of bridges.

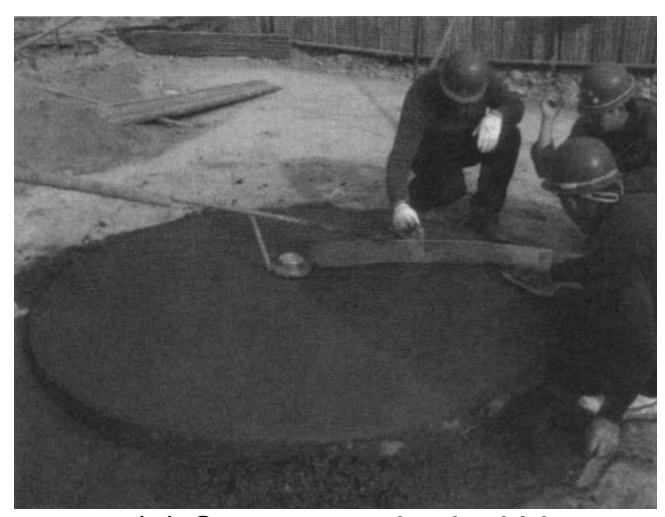

(a) Concrete spherical hinge

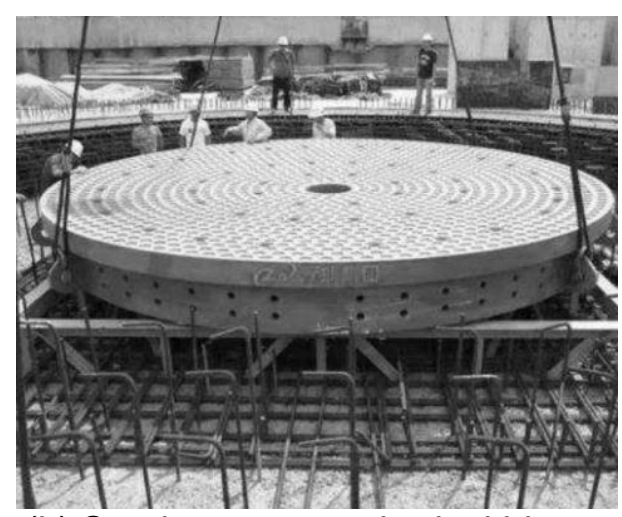

(b) Steel structure spherical hinge

Fig. 1 - Traditional spherical hinges

\section{RESEARCH METHOD}

\section{Project overview}

This paper takes a continuous rigid frame bridge with variable beam height as the research object, with a span of $2 \times 62 \mathrm{~m}$ and a maximum cantilever length of $62 \mathrm{~m}$ on one side. The main beam adopts C50 concrete single box three-chamber inclined web box section. The top plate of the box girder is $21.3 \mathrm{~m}$ wide, and the cantilever length of the flange plates on both sides is $3 \mathrm{~m}$. The end thickness of the cantilever plate is $20 \mathrm{~cm}$, the root thickness is $50 \mathrm{~cm}$, the top plate thickness of the 


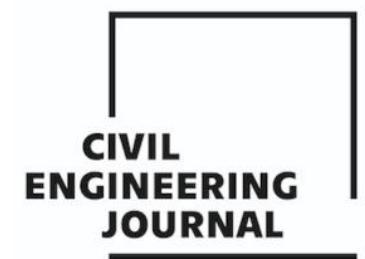

Article no. 35

THE CIVIL ENGINEERING JOURNAL 2-2021

middle fulcrum box beam is $70 \mathrm{~cm}$, and the bottom plate thickness is $190 \mathrm{~cm}$. The beam height of the fulcrum is $6 \mathrm{~m}$, the beam height of the side span straight section $2 \mathrm{~m}$, and the rotating weight is about 10,000 t. The spherical hinge structure adopts UHPC spherical hinge. The dimensions of each part of the swivel system are shown in Figure 2.

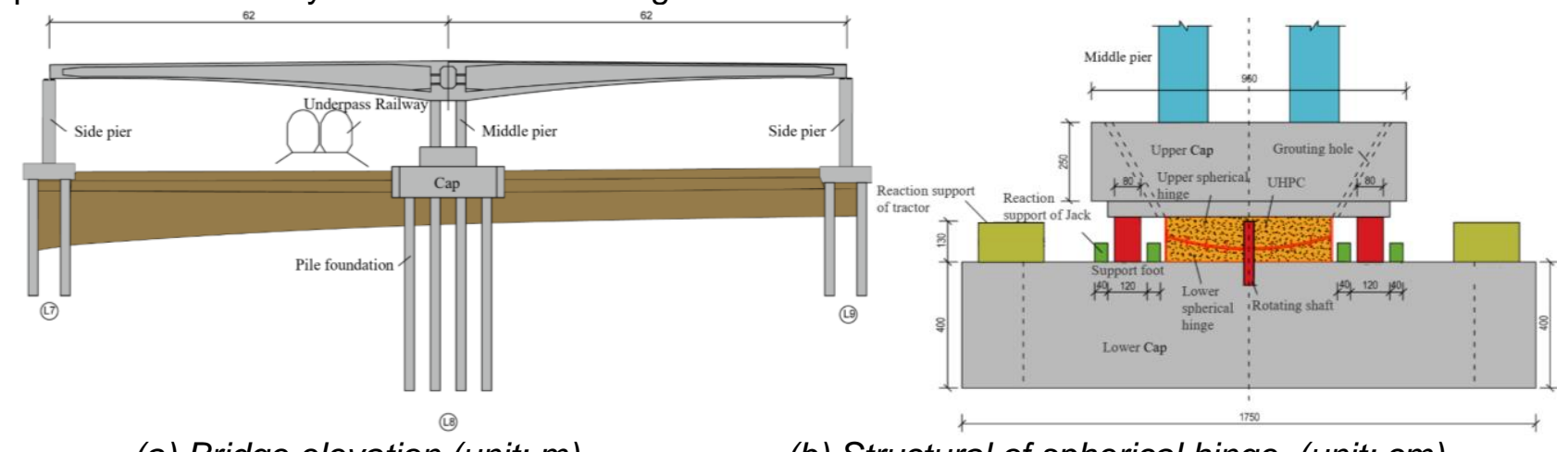

(a) Bridge elevation (unit: $m$ )

(b) Structural of spherical hinge (unit: $\mathrm{cm}$ )

Fig.2 - Dimensions of each part of the swivel system

\section{Establishment of structural simulation model}

This paper uses the application ANSYS for simulation analysis: in the swivel model, the pier and the main beam are consolidated together to form the maximum cantilever state; the two ends of the bridge are in an unconstrained state, the spherical hinges and the footing structure support the entire rotating structure. The model in the maximum cantilever state of the structure is Model 1, as shown in Figure 3-a. After rotating into a certain point, the cantilever ends are connected with the supports on the piers on both sides, the outer concrete of the spherical hinge is closed, and the joint transforms into a consolidated state. The structure of the bridge state model is Model 2, as shown in Figure 3b. When the time history analysis method is used to calculate the response of the structure to the seismic action, the load step of a single seismic wave exceeds 10,000 steps. At the same time, geometric nonlinearity and material nonlinearity should be taken into consideration when analyzing the finite element simulation analysis. In order to simplify the calculation and improve the efficiency of analysis, this study adopts the overall model when calculating the internal force response of the structure, as shown in Figure 4-a. The local model analysis is used to calculate the influence of the spherical hinge and the footing structure on the stability of the system, as shown in Figure 4-b.

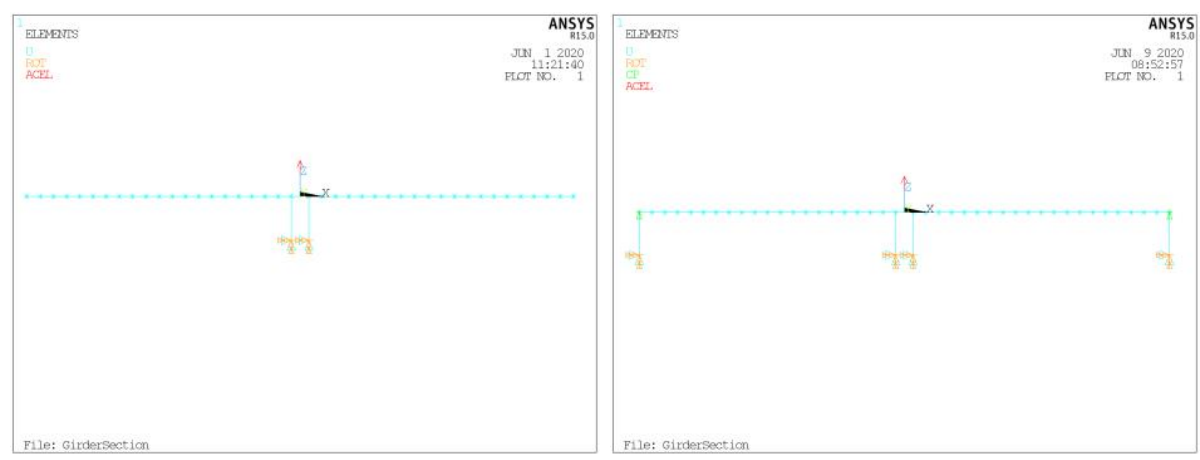

(a) Model 1

(b) Model 2

Fig.3 - Two analysis models 


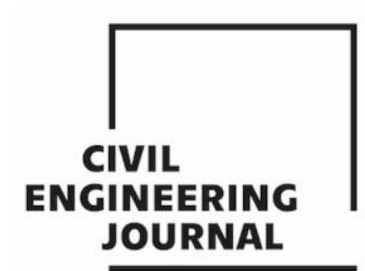

Article no. 35

THE CIVIL ENGINEERING JOURNAL 2-2021

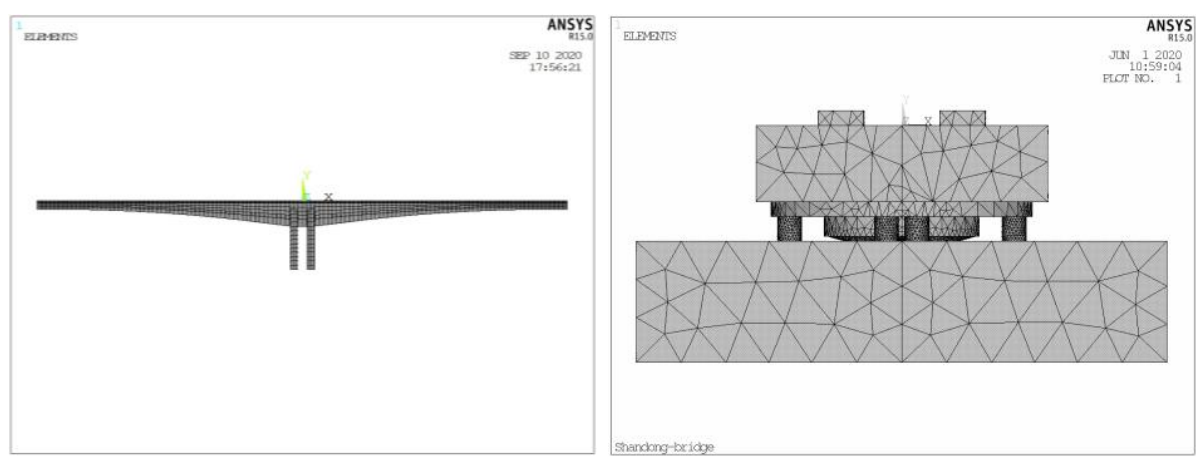

(a) Discrete graph of overall model

(b) Discrete graph of local model

Fig. 4 - Overall model and local model

The Beam 188 element is used for the main beam and bridge pier, and the element has a threedimensional finite strain structure with two nodes. Each node has 6 degrees of freedom (3 translational degrees of freedom and 3 rotational degrees of freedom). In order to simulate the connection form between the bridge pier and the main girder, MPC184 unit was used for simulation. In the maximum cantilever state, the structure of the system is only restricted by the spherical hinge structure: the spherical hinge provides vertical force support, and the other footing structures provide lateral and longitudinal bending moment support, the overall structure in a balanced state. Finally, the Model 1 adopts a consolidation treatment at the bottom of the pier. In Model 2, the influence of side pier constraints on the structure is taken into consideration. Hence, we set vertical and horizontal general supports on the top of the pier and adopt Solid65 unit in the structure of the upper and lower spherical hinges and footing structures.

In structural dynamic time history analysis, how structural damping is defined is very important. structural damping is proportional to the speed of the structure. When the transient analysis is used in the ANSYS solver, the structural damping is Rayleigh damping [14], and its expression is shown in equation (1).

$$
[C]=\alpha[M]+\beta[K]
$$

In the above equation, $[C]$ is the damping matrix, $[M]$ is the mass matrix, while $[K]$ is the stiffness matrix, $\alpha$ the mass damping coefficient, and $\beta$ the stiffness matrix coefficient. The relationship between the coefficient $\alpha, \beta$ and the viscosity proportional coefficient $\xi$ is shown below:

$$
\alpha /(2 \times \omega)+\beta \times \omega / 2=\xi
$$

In the formula: $\omega$ is the circular frequency, and $f$ is the structure frequency, and $\omega=2 \pi f$. Two equations are obtained through structural modal calculation:

$$
\begin{aligned}
& \alpha /(2 \times \omega 1)+\beta \times \omega 1 / 2=\xi \\
& \alpha /(2 \times \omega 2)+\beta \times \omega 2 / 2=\xi
\end{aligned}
$$

Combine the above formulas, the following equation is obtained.

$$
\begin{gathered}
\alpha=4 \times \pi \times f_{1} \times f_{2} \times \xi /\left(f_{1}+f_{2}\right) \\
\beta=2 \times \xi /\left(\omega_{1}+\omega_{2}\right)=\xi / \pi /\left(f_{1}+f_{2}\right)
\end{gathered}
$$

\section{Structural mode shape calculation}

It is known that the dynamic characteristics of the structure are affected by the mass distribution and the boundary conditions of the structure. For the same order, Model 1 and Model 2 have different modal frequencies. The Lanczos method is used to calculate the first 10 modes of the structure, and the structure quality participation coefficient is over $95 \%$. Vibration frequency and vibration form are shown in Table 1. 


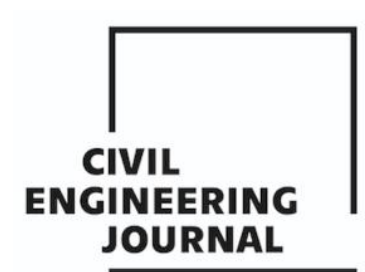

Article no. 35

THE CIVIL ENGINEERING JOURNAL 2-2021

Tab. 1 - Frequencies and modes of the first ten modes of the structure

\begin{tabular}{|c|c|c|c|c|}
\hline \multirow{2}{*}{$\begin{array}{l}\text { Mode } \\
\text { number }\end{array}$} & \multicolumn{2}{|c|}{ Frequency/Hz } & \multicolumn{2}{|c|}{ Vibration form } \\
\hline & $\begin{array}{c}\text { Model } \\
1\end{array}$ & $\begin{array}{l}\text { Model } \\
2\end{array}$ & Model 1 & Model 2 \\
\hline 1 & 0.390 & 1.826 & $\begin{array}{l}\text { the beam bent transversely, the } 1^{\text {st }} \text { mode; } \\
\text { the middle pier bent transversely, the } 1^{\text {st }} \text { mode }\end{array}$ & $\begin{array}{l}\text { middle pier bent longitudinally, the } 1^{\text {st }} \\
\text { mode }\end{array}$ \\
\hline 2 & 0.491 & 2.358 & the beam bent longitudinally, the $1^{\text {st }}$ mode & side piers bent transversely, the $1^{\text {st }}$ mode \\
\hline 3 & 0.810 & 2.713 & the beam bent longitudinally, the $2^{\text {nd }}$ mode & $\begin{array}{l}\text { the main beam bent longitudinally, the } 1^{\text {st }} \\
\text { mode }\end{array}$ \\
\hline 4 & 1.870 & 3.240 & middle pier bent longitudinally, the $1^{\text {st }}$ mode & side piers bent transversely, the $2^{\text {nd }}$ mode \\
\hline 5 & 2.107 & 3.322 & The beam bent transversely, the $2^{\text {nd }}$ mode & beam bent longitudinally, the $2^{\text {nd }}$ mode \\
\hline 6 & 3.905 & 6.340 & the beam bent longitudinal, the $3^{\text {rd }}$ mode & $\begin{array}{l}\text { middle pier bent transversely, } 1^{\text {st }} \text { mode; } \\
\text { side pier bent horizontally, the } 3^{\text {rd }} \text { mode }\end{array}$ \\
\hline 7 & 4.060 & 7.912 & $\begin{array}{l}\text { the beam twisted, the } 1^{\text {st }} \text { mode; } \\
\text { the middle pier bent transversely, the } 2^{\text {nd }} \\
\text { mode }\end{array}$ & the main beam twisted, the $1^{\text {st }}$ mode \\
\hline 8 & 4.605 & 8.603 & the main beam twisted, the $2^{\text {nd }}$ mode & $\begin{array}{l}\text { the main beam bent longitudinally, the } 3^{\text {rd }} \\
\text { mode }\end{array}$ \\
\hline 9 & 4.637 & 8.721 & $\begin{array}{l}\text { the main beam bent longitudinally, the } 4^{\text {th }} \\
\text { mode }\end{array}$ & $\begin{array}{l}\text { the main beam bent longitudinally, the } 2^{\text {nd }} \\
\text { mode }\end{array}$ \\
\hline 10 & 7.340 & 9.340 & the main beam twisted, the $3^{\text {rd }}$ mode & side piers bent transversely, the $3^{\text {rd }}$ mode \\
\hline
\end{tabular}

\section{Earthquake input}

The input process of earthquake is the main influencing factor of seismic response analysis. Time history analysis selects actual strong earthquake records or artificially simulated acceleration time history according to the type of site. At the same time, it is required that the actual seismic records should not be less than $2 / 3$ of the total. The average value of the shear force at the bottom of the pier calculated by multiple seismic waves should not be less than $80 \%$ of the calculation result of response spectrum method [15-16]. In order to obtain the true response of the continuous rigid frame bridge under the maximum cantilever state, all seismic waves recorded by actual strong earthquakes are used in the study, and the maximum value is used as the calculation basis. The actual strong earthquake record is based on the seismic database of the Pacific Earthquake Engineering Research Center(PEER). By inputting the design response spectrum and the first threeorder natural vibration period of the structure, multiple sets of suitable seismic waves are screened out. The actual response spectrum is obtained by Fourier transform, and the acceleration value under the first-order natural vibration period is compared with the designed response spectrum. The difference between the two should not be greater than 35\%. Seismic waves are screened based on this principle. According to the screening results, it is found that the seismic records in three directions under the same set of ground motions: HMC180, HMC270, HMCDWN, are difficult to meet the requirement of less than $35 \%$ error at the same time under the first-order natural vibration period. Therefore, the seismic waves of Model 1 and 2 in the three directions are respectively different seismic data, and finally 18 seismic waves that meet the requirements are screened out of 50 strong earthquake records. This paper uses the acceleration response spectrum in the "Detailed Rules for Seismic Resistance of Highway Bridges" [16] as the comparative data for time history analysis, and the response spectrum is shown in equation (4).

$$
s=\left\{\begin{array}{c}
S_{A \max } \times(5.5 T+0.45) \quad T<0.1 s \\
S_{A \max } 0.1 s \leq T \leq T_{g} \\
S_{A \max } \times\left(T_{g} / T\right) T>T_{g}
\end{array}\right.
$$

$S_{A \max }$ is the maximum seismic acceleration, while $T_{g}$ is the characteristic period, $T$ is the natural vibration period.

The actual seismic waves are screened through the characteristic period and the first threeorder natural frequencies of the structure. All in all, there are two directions in the two models and a 
total of 18 real seismic waves are screened. The acceleration time history curves of Model 1 and the seismic wave response spectrum after Fourier transformation are shown in Figure 5 and Figure 6.

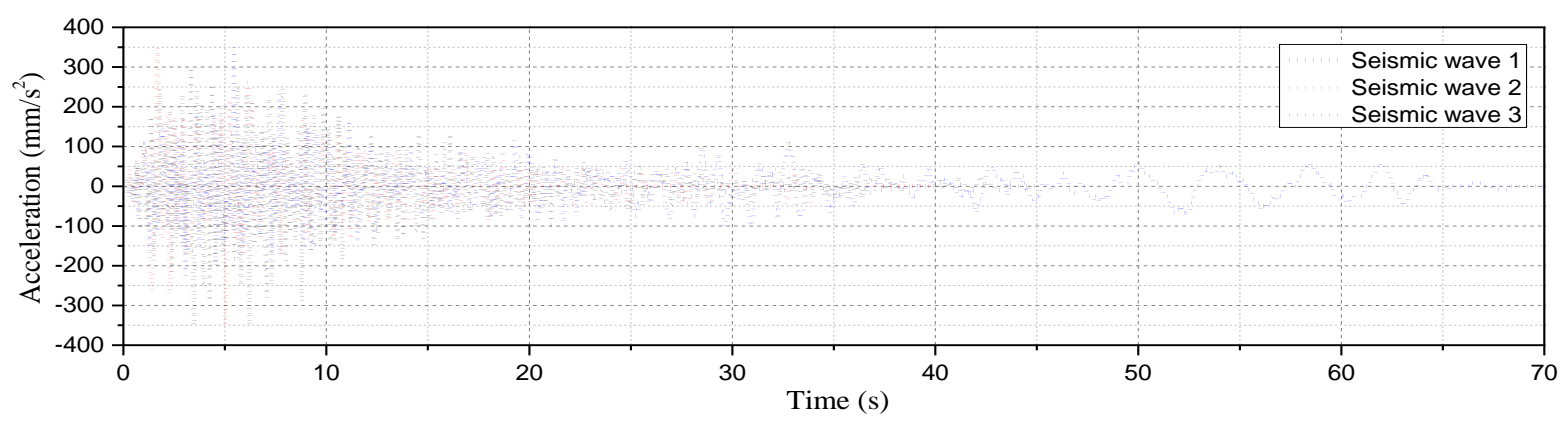

Fig.5 - Transerse seismic wave acceleration time history curve of Model 1

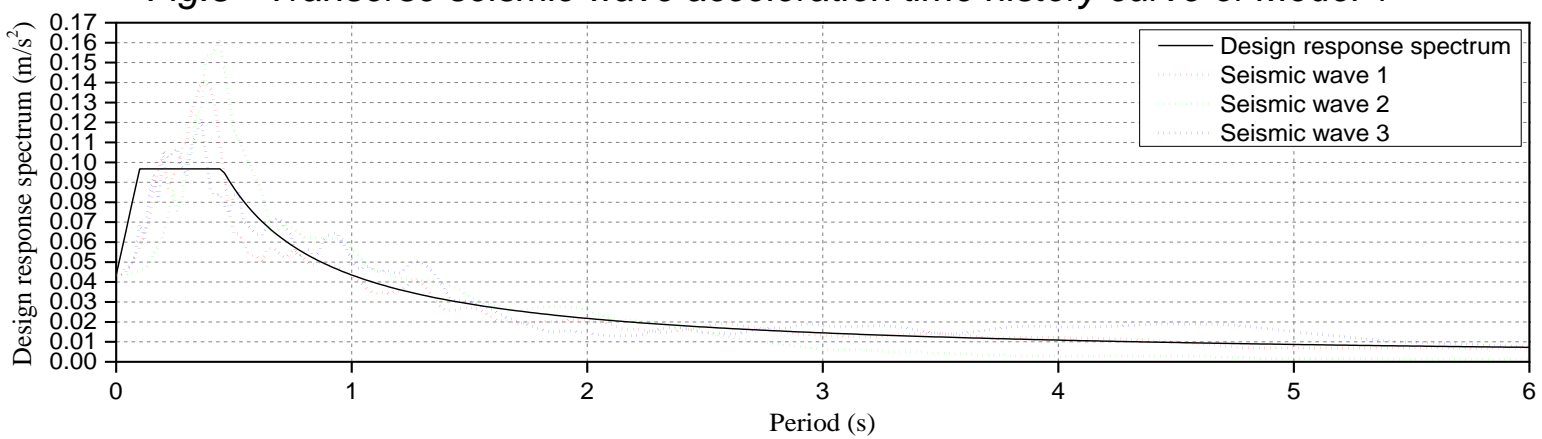

Fig.6 - Transverse seismic wave response spectrum of Model 1

It can be seen from the above figures (Figure 5 to Figure 6 ) that the seismic wave time history curve is relatively random, and the earthquake duration is different, ranging from 30 s to $70 \mathrm{~s}$. What is for sure is that the duration of the earthquake is more than 5 times the basic period of the structure. The first-order natural vibration period of Model 1 is $2.56 \mathrm{~s}$; the corresponding design response spectrum acceleration is $0.017 \mathrm{~g}$, and the absolute value of the seismic wave error in the three directions is $11.8 \%-23.5 \%$. The first-order natural vibration period of Model 2 is $0.55 \mathrm{~s}$; the corresponding design response spectrum acceleration value is $0.1 \mathrm{~g}$, and the absolute value of the error in the three directions is $1.0 \%-23.7 \%$; all meet the screening requirements.

\section{RESULTS AND DISCUSSION}

\section{Simulation results}

\section{Seismic response analysis of Model 1}

We performed nonlinear dynamic time history analysis on the two models, and compared the time history analysis results with the calculation results of the response spectrum method. It is necessary to consider the time integration function in ANSYS when calculating, otherwise the cumulative effect of seismic action cannot be considered. The time step of the seismic wave is $0.005 \mathrm{~s}$, and the calculation step should be consistent with the seismic wave record. The internal force response of Model 1 is shown in the following tables (Table 2 to Table 4). 


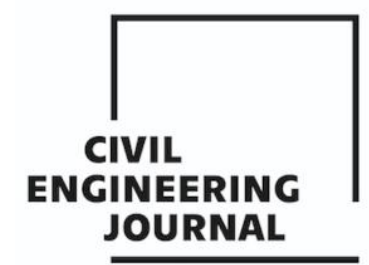

Article no. 35

THE CIVIL ENGINEERING JOURNAL 2-2021

Tab. 2 - Transverse seismic response of the bridge (force unit: $k N$, moment unit: $k N \cdot m$ )

\begin{tabular}{|c|c|c|c|c|c|c|c|}
\hline Location & Internal force & $\begin{array}{l}\text { Seismic } \\
\text { wave } 1\end{array}$ & $\begin{array}{l}\text { Seismic } \\
\text { wave } 2\end{array}$ & $\begin{array}{l}\text { Seismic } \\
\text { wave } 3\end{array}$ & Max & Average & $\begin{array}{c}\text { Response } \\
\text { spectrum results }\end{array}$ \\
\hline \multirow{2}{*}{ Pier top } & shear force $F y$ & 1820 & 3104 & 1747 & 3104 & 2224 & 3080 \\
\hline & bending moment $M x$ & 15500 & 25540 & 15970 & 25540 & 19003 & 16269 \\
\hline \multirow{2}{*}{ Pier bottom } & shear force $F y$ & 1900 & 3204 & 1785 & 3204 & 2296 & 3065 \\
\hline & bending moment $M x$ & 19000 & 33025 & 18736 & 33025 & 23587 & 19913 \\
\hline \multirow{2}{*}{$\begin{array}{c}\text { Cantilever } \\
\text { root }\end{array}$} & shear force $F y$ & 1712 & 2970 & 1536 & 2970 & 2073 & 2300 \\
\hline & bending moment $M z$ & 68460 & 101477 & 62485 & 101477 & 77474 & 60736 \\
\hline
\end{tabular}

Tab. 3 - Longitudinal bridge seismic response (force unit: $k N$, moment unit: $k N \cdot m$ )

\begin{tabular}{cccccccc}
\hline \multirow{2}{*}{ Location } & Internal force & $\begin{array}{c}\text { Seismic } \\
\text { wave 1 }\end{array}$ & $\begin{array}{c}\text { Seismic } \\
\text { wave 2 }\end{array}$ & $\begin{array}{c}\text { Seismic } \\
\text { wave 3 }\end{array}$ & Max & $\begin{array}{c}\text { Average } \\
\text { Response } \\
\text { spectrum } \\
\text { results }\end{array}$ \\
\hline \multirow{2}{*}{ Pier top } & axial force $F z$ & 2432 & 1416 & 1383 & 2432 & 1744 & 1789 \\
& shear force $F x$ & 2700 & 1028 & 1413 & 2700 & 1714 & 1350 \\
& bending moment $M y$ & 13317 & 5045 & 7019 & 13317 & 8460 & 7930 \\
Pier bottom & axial force $F z$ & 2433 & 1417 & 1383 & 2433 & 1744 & 1800 \\
& shear force $F x$ & 2797 & 921 & 1400 & 2797 & 1706 & 2300 \\
Cantilever root & bending moment $M y$ & 14303 & 5425 & 7362 & 14303 & 9030 & 11760 \\
\hline
\end{tabular}

Tab. 4 - Vertical seismic response (force unit: $k N$, moment unit: $k N \cdot m$ )

\begin{tabular}{|c|c|c|c|c|c|c|c|}
\hline Location & Internal force & $\begin{array}{l}\text { Seismic } \\
\text { wave } 1\end{array}$ & $\begin{array}{l}\text { Seismic } \\
\text { wave } 2\end{array}$ & $\begin{array}{l}\text { Seismic } \\
\text { wave } 3\end{array}$ & $\operatorname{Max}$ & Average & $\begin{array}{c}\text { response spectrum } \\
\text { results }\end{array}$ \\
\hline \multirow{3}{*}{ pier top } & axial force $F z$ & 7610 & 9300 & 7610 & 9300 & 8173 & 6080 \\
\hline & shear force $F x$ & 58 & 100 & 87 & 100 & 82 & 26 \\
\hline & bending moment $M y$ & 419 & 673 & 587 & 673 & 560 & 215 \\
\hline \multirow{3}{*}{$\begin{array}{c}\text { pier } \\
\text { bottom }\end{array}$} & axial force $F z$ & 8370 & 9700 & 7710 & 9700 & 8593 & 7438 \\
\hline & shear force $F x$ & 62 & 100 & 88 & 100 & 83 & 39 \\
\hline & bending moment $M y$ & 200 & 321 & 280 & 321 & 267 & 147 \\
\hline \multirow{2}{*}{$\begin{array}{c}\text { cantileve } \\
\text { r root }\end{array}$} & shear force $F z$ & 7190 & 9100 & 7550 & 9100 & 7947 & 6695 \\
\hline & bending moment $M y$ & 21451 & 34483 & 30085 & 34483 & 28673 & 21744 \\
\hline
\end{tabular}

From the above tables, we can see:

(1) Under lateral seismic input, the main response of the earthquake is the lateral bending moment from the pier bottom, the lateral shear force and the lateral bending moment of the main beam. The internal force at the top of the pier is less than that at the bottom of the pier, the axial force at the pier and the main girder are very small, and the transverse bending moment at the bottom of the pier is the controlling parameter. The calculation results of the three seismic waves are highly discrete, and their average results are close to the calculation results of the response spectrum.

(2) Under longitudinal seismic input, the main seismic response is the longitudinal bending moment at the bottom and top of the pier. Under this working condition, the longitudinal bending 


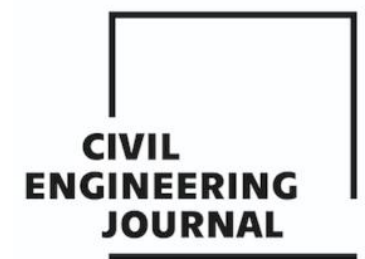

Article no. 35

THE CIVIL ENGINEERING JOURNAL 2-2021

moment of the bridge pier and the longitudinal bending moment of the cantilever root of the main beam are the control parameters. The calculation results of the three seismic waves are highly discrete. Among them, the calculation result of the first wave is about twice that of the other two waves, and the average result is close to the calculation result of the response spectrum.

(3) Under the vertical seismic input, the main seismic response is the axial force of the bridge pier and the longitudinal bending moment at the root of the main girder cantilever. The longitudinal bending moment has exceeded the seismic response in the longitudinal direction. The vertical axial force of the bridge pier and the longitudinal bending moment at the root of the main beam cantilever are the control parameters. The calculation results of the three seismic waves are relatively close, exceeding the calculation results of the response spectrum in the axial force response and the bending moment response.

In order to obtain the most unfavourable result of seismic action, this study selects the maximum value in the time history analysis as the calculation basis. According to the results, the internal force time history curve of each control section is shown in Figure 7 and 8.

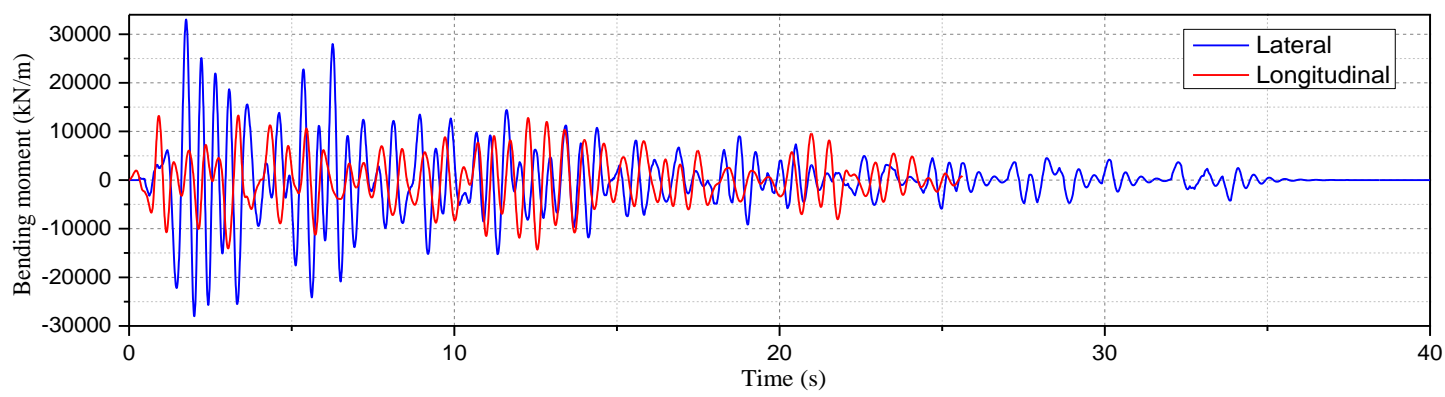

(a) Time history of bending moment

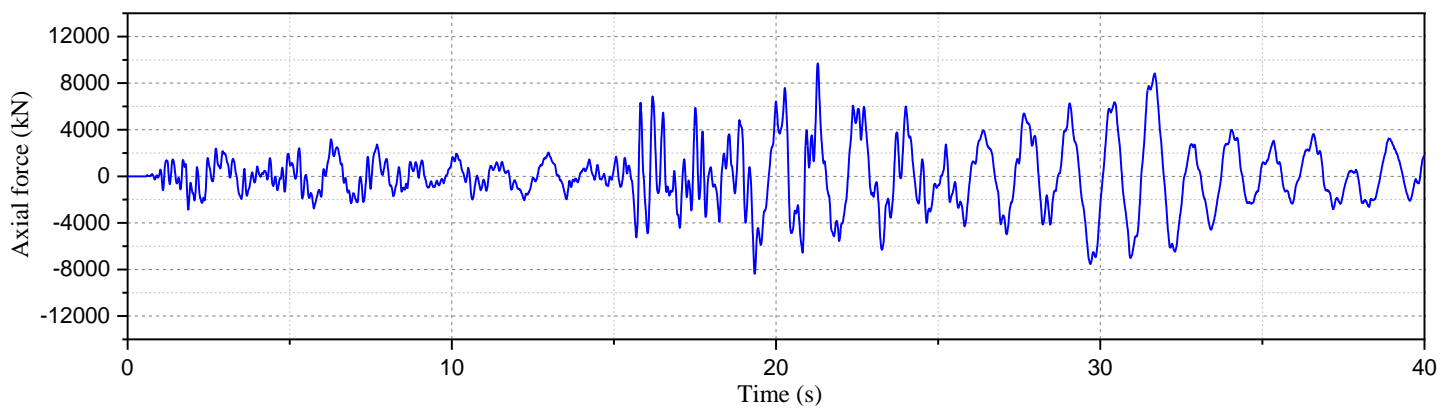

(b) Time history of axial force

Fig. 7 - Internal force time history curve of the pier bottom

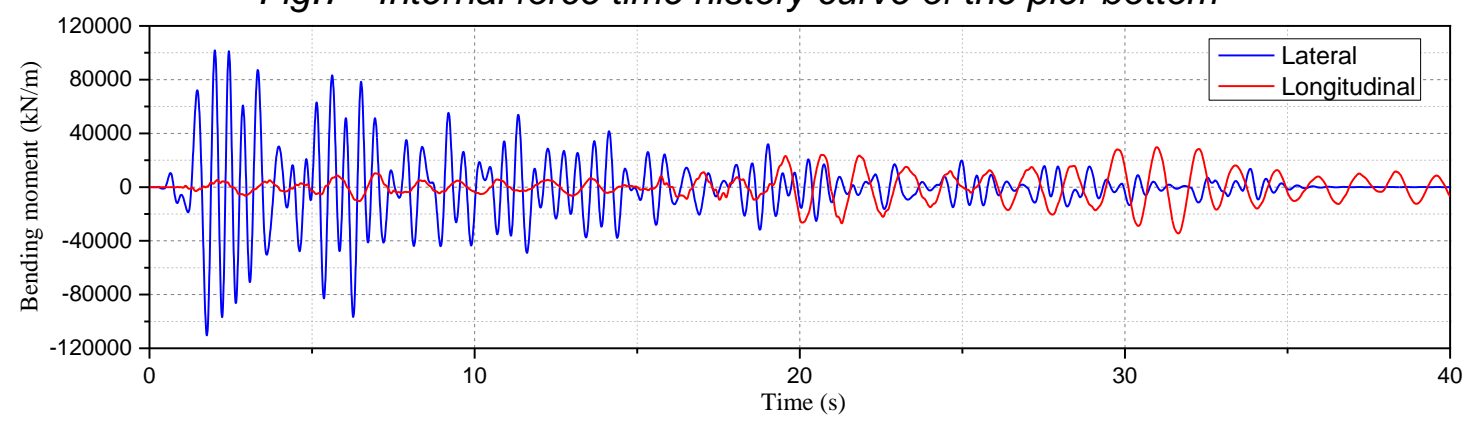

Fig. 8 - Internal force time history curve of the beam

Under the action of three-dimensional earthquakes, the rotating structure will bend in the transverse and along the bridge direction and be compressed in the vertical direction. The axial force is borne by the UHPC spherical hinge, and the transverse as well as longitudinal bending moments are borne by the friction moment of the spherical hinge and the anti-overturning moment produced by the pressure between the footing structure and the slide way. Load the internal force of the pier 


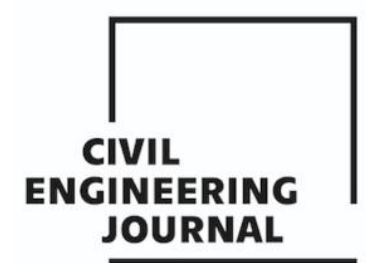

Article no. 35

THE CIVIL ENGINEERING JOURNAL 2-2021

bottom into the local model, calculate the force of the UHPC spherical hinge and the footing structure, the UHPC spherical hinge compressive stress is shown in Figure 9 and Figure 10.

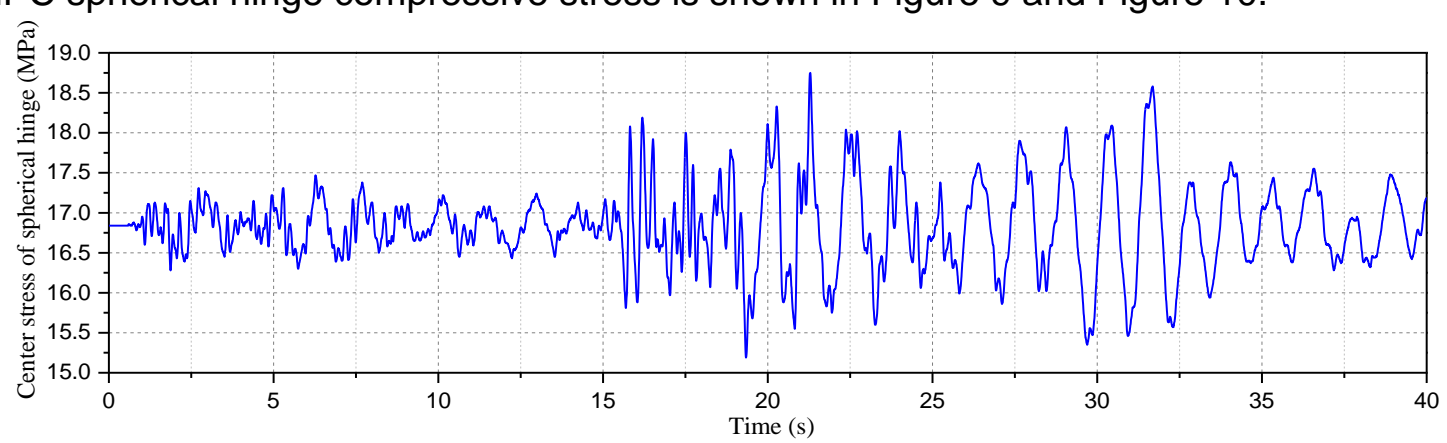

Fig.9 - Time history of central compressive stress of UHPC spherical hinge

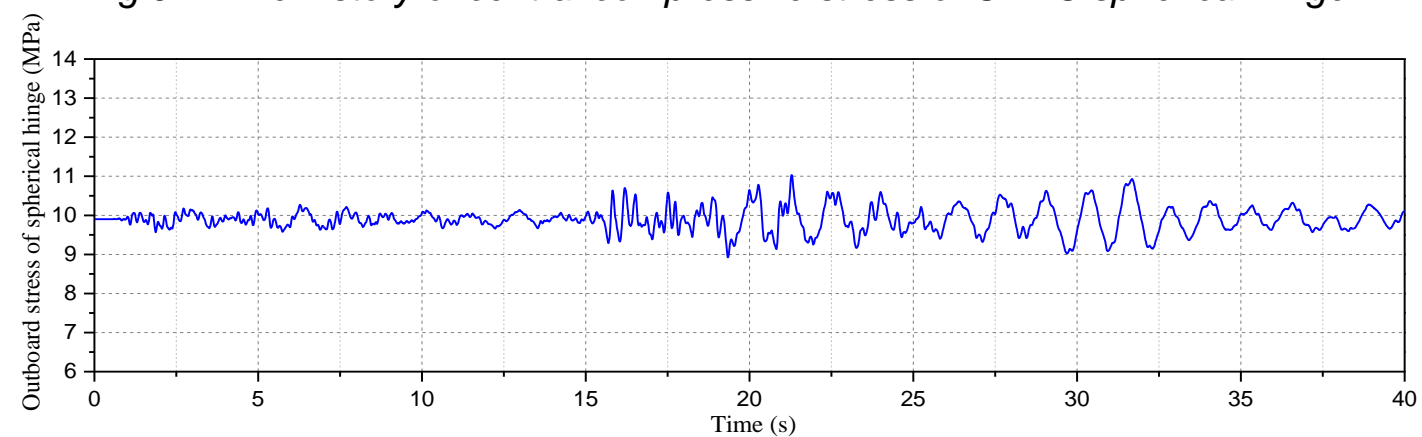

Fig.10 - Time history of the compressive stress on outer edge of UHPC spherical hinge

It can be seen from Figure 9 and Figure 10 that the compressive stress of the spherical hinge changes with the vertical seismic action: the central compressive stress of the spherical hinge floats on the straight line $y=16.84 \mathrm{MPa}$ from which it can be obtained that the maximum compressive stress is $18.75 \mathrm{MPa}$, and that the minimum compressive stress is $15.19 \mathrm{MPa}$. Among them, $16.84 \mathrm{MPa}$ is the compressive stress value of the spherical hinge under its own weight load, and the range of change is $-9.8 \%$ to $11.3 \%$. The compressive stress of the outer edge of the spherical hinge fluctuates in the straight line $y=9.9 \mathrm{MPa}$ in which the maximum compressive stress is $11.03 \mathrm{MPa}$ and the minimum compressive stress is $8.93 \mathrm{MPa}$, and the value of change ranges from $-9.7 \%$ to $11.4 \%$. The compressive stress of the spherical hinge under seismic action is about $11 \%$. According to the research results of the literature $[9,11]$, when the compressive strength of the UHPC spherical hinge is above $200 \mathrm{MPa}$, its compressive strength shall meet the seismic requirements of the bridge.

Under the action of vertical earthquake and its own weight, the pier is under axial compression, and its vertical compressive stress is all borne by the spherical hinge. At this time, the compressive stress of the supporting structure is basically zero. According to the results of the internal force time history of the pier, lateral bending is the most unfavourable response of the pier. The lateral bending moment at the bottom of the pier will be transmitted to the position of the spherical hinge through the cap, and the frictional resistance of the spherical hinge and the anti-overturning moment of the footing structure will be shared. The friction moment of UHPC spherical hinge is shown in Figure 11, and the stress is shown in Figure 12. 


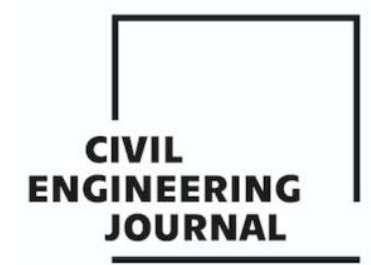

Article no. 35

THE CIVIL ENGINEERING JOURNAL 2-2021

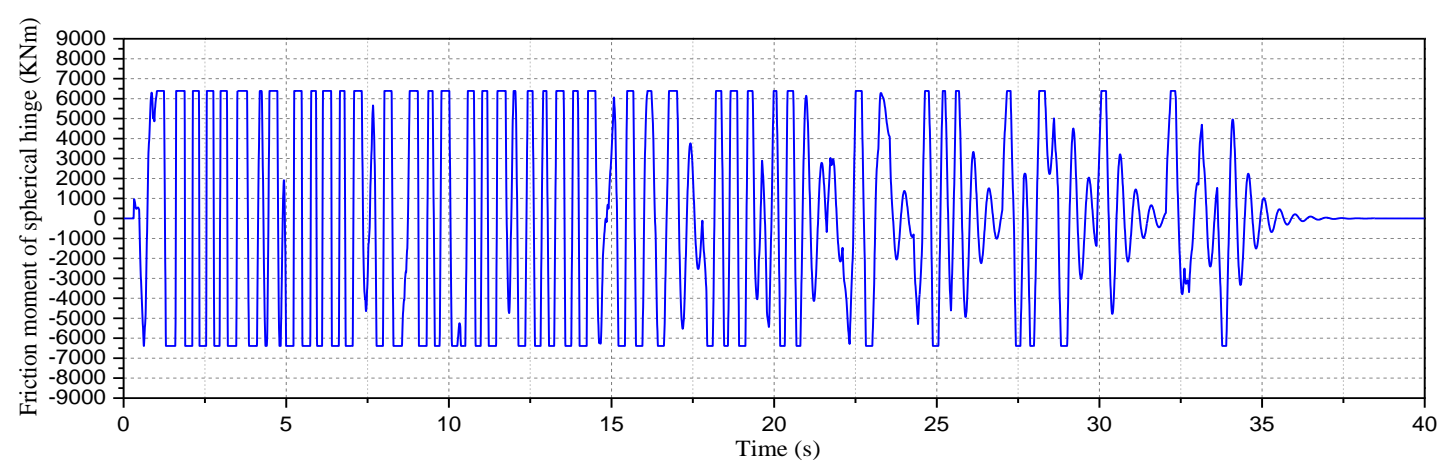

Fig.11 - Time history of friction moment of UHPC spherical hinge

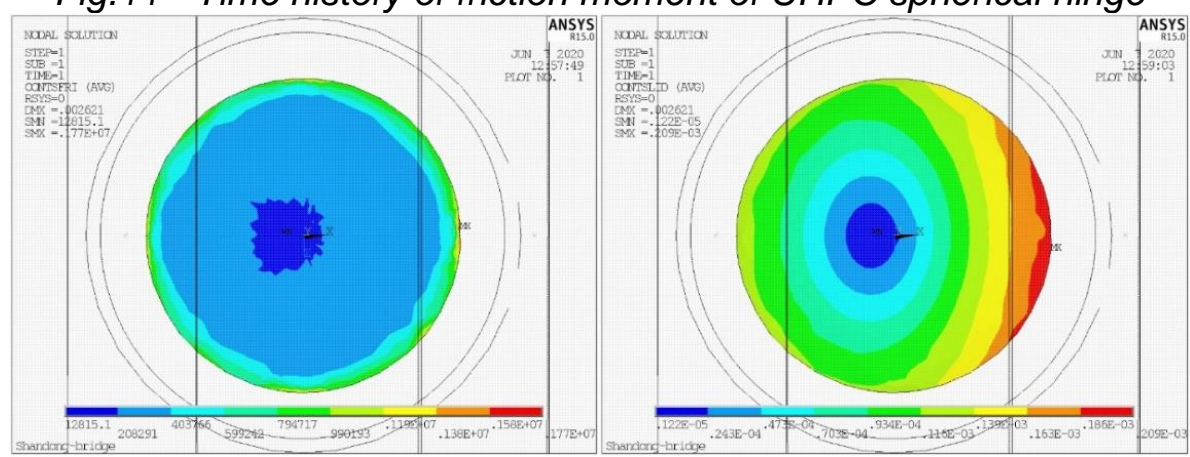

(a) Friction stress

(b) Sliding displacement

Fig. 12 - Stress of UHPC spherical hinge

Figure 11 shows that the friction moment curve of the spherical hinge has obvious "peak clipping". The maximum bending moment at the bottom of the pier is $33025 \mathrm{kN} \cdot \mathrm{m}$, while the maximum friction moment of the spherical hinge fluctuates around $6300 \mathrm{kN} \cdot \mathrm{m}$. At this time, the spherical hinge reaches its limit state. Figure 12 is a diagram of the frictional stress and sliding displacement of the spherical hinge in the limit state. The contact surface of the spherical hinge slides along the bending moment, and the maximum sliding distance is $0.209 \mathrm{~mm}$. At this time, the bending moment transferred from the pier will be transferred to the footing structure through the upper cap, and the footing structure will contact the slideway to generate axial stress. The compressive stress diagram in the axial direction of the footing structure is shown in Figure 13.

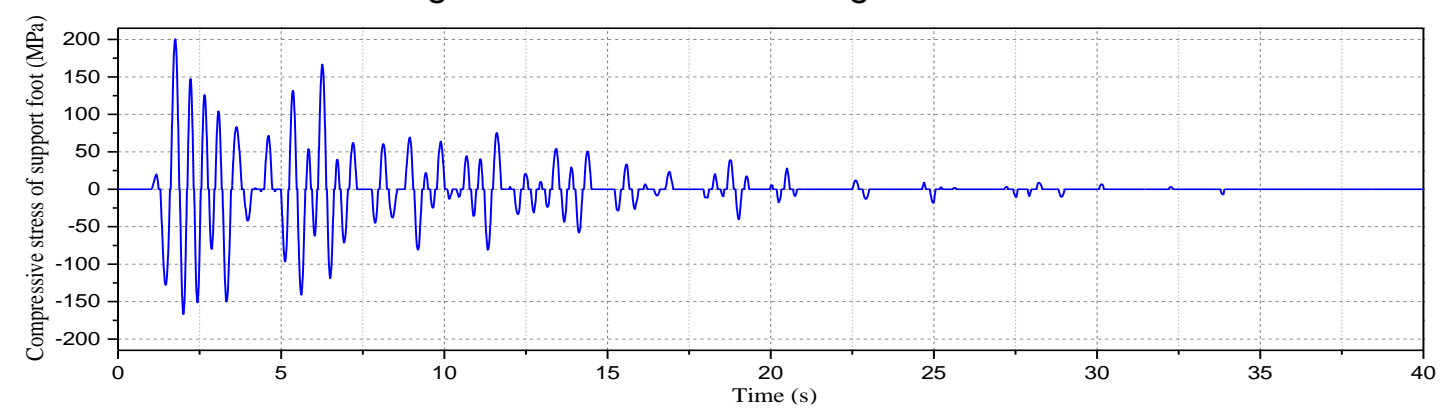

Fig.13- Pressure stress time history of the footing structure

When the compressive stress is positive, the compressive stress of the footing structures is calculated; when the stress value is negative, the calculated side compressive stress is 0 , and it produces axial compressive stress on the opposite side of the supporting structures. It can be seen from Figure 13 that the calculated maximum compressive stress of the side brace is $200.6 \mathrm{MPa}$, and the maximum compressive stress of the opposite side is $166.9 \mathrm{MPa}$. At this time, the steel pipe of the section of the footing structures produces a large compressive stress under the action of the lateral earthquake. The footing structures are used as the safety reserve of the structure during the 


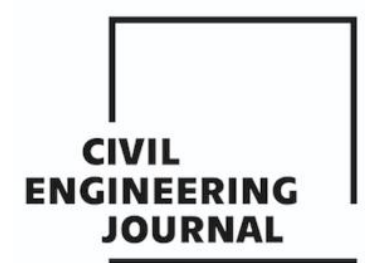

Article no. 35

THE CIVIL ENGINEERING JOURNAL 2-2021

design and construction of the rotating bridge; the structural stability of the supporting structure is thus usually ignored.

\section{Seismic response analysis of Model 2}

The internal force response of the key section under three-way seismic input of Model 2 is shown in the following tables (Table 5 to Table 7).

Tab. 5 - Transverse seismic response of the bridge(force Unit: $k N$, bending moment unit: $k N \cdot m$ )

\begin{tabular}{cccccccc}
\hline Location & Internal force & $\begin{array}{c}\text { Seismic } \\
\text { wave 1 }\end{array}$ & $\begin{array}{c}\text { Seismic } \\
\text { wave 2 }\end{array}$ & $\begin{array}{c}\text { Seismic } \\
\text { wave 3 }\end{array}$ & Max & Average & $\begin{array}{c}\text { Response } \\
\text { spectrum }\end{array}$ \\
\hline \multirow{2}{*}{ Pier top } & shear force Fy & 2192 & 2445 & 2832 & 2832 & 2490 & 2983 \\
& bending moment $M x$ & 1763 & 2608 & 2295 & 2608 & 2222 & 2530 \\
Pier bottom & shear force Fy & 2243 & 2527 & 2940 & 2940 & 2570 & 3752 \\
& bending moment $M x$ & 21487 & 23913 & 26932 & 26932 & 24111 & 18075 \\
$\begin{array}{c}\text { Cantilever } \\
\text { root }\end{array}$ & shear force Fy & 2139 & 2374 & 2751 & 2751 & 2421 & 2552 \\
\hline
\end{tabular}

Tab. 6 - Response of the longitudinal bridge seismic

\begin{tabular}{cccccccc}
\hline Location & Internal force & $\begin{array}{c}\text { Seismic } \\
\text { wave 1 }\end{array}$ & $\begin{array}{c}\text { Seismic } \\
\text { wave 2 }\end{array}$ & $\begin{array}{c}\text { Seismic } \\
\text { wave 3 }\end{array}$ & Max & $\begin{array}{c}\text { Average } \\
\text { Response } \\
\text { spectrum }\end{array}$ \\
\hline \multirow{3}{*}{ Pier top } & Axial force $F z$ & 5915 & 5423 & 6429 & 6429 & 5922 & 5550 \\
& Shear force $F x$ & 3675 & 2385 & 4238 & 4238 & 3433 & 3370 \\
& Bending moment $M y$ & 17725 & 11836 & 20553 & 20553 & 16705 & 15320 \\
\multirow{2}{*}{$\begin{array}{c}\text { Pier bottom } \\
\text { Cantilever } \\
\text { root }\end{array}$} & Axial force Fz & 5919 & 5428 & 6432 & 6432 & 5926 & 5152 \\
\hline
\end{tabular}

Tab. 7- Response of the vertical seismic (force Unit: $k N$, bending moment unit: $k N \cdot m$ )

\begin{tabular}{|c|c|c|c|c|c|c|c|}
\hline Location & Internal force & $\begin{array}{l}\text { Seismic } \\
\text { wave } 1\end{array}$ & $\begin{array}{l}\text { Seismic } \\
\text { wave } 2\end{array}$ & $\begin{array}{l}\text { Seismic } \\
\text { wave } 3\end{array}$ & Max & Average & $\begin{array}{l}\text { Response } \\
\text { spectrum }\end{array}$ \\
\hline \multirow{3}{*}{ Pier top } & Axial force $F z$ & 1410 & 1464 & 730 & 1464 & 1201 & 1230 \\
\hline & Shear force $F x$ & 49 & 51 & 28 & 51 & 43 & 100 \\
\hline & Bending moment $M y$ & 334 & 362 & 189 & 362 & 295 & 505 \\
\hline \multirow{3}{*}{ Pier bottom } & Axial force $F z$ & 1471 & 1504 & 739 & 1504 & 1238 & 1323 \\
\hline & Shear force $F x$ & 50 & 55 & 28 & 55 & 44 & 112 \\
\hline & Bending moment $M y$ & 103 & 174 & 91 & 174 & 123 & 215 \\
\hline \multirow{2}{*}{$\begin{array}{c}\text { Cantilever } \\
\text { root }\end{array}$} & Shear force $F z$ & 1375 & 1441 & 726 & 1441 & 1181 & 1235 \\
\hline & Bending moment $M y$ & 17192 & 18621 & 9710 & 18621 & 15174 & 17300 \\
\hline
\end{tabular}

The calculation results show that the seismic response of Model 1 at each control section is greater than that of Model 2. The bottom of the pier of Model 1 is consolidated, and the cantilever end of the main girder is a free end. As to Model 2, it applies vertical and lateral translational constraints at the cantilever end of the main girder through basin rubber bearings on both sides of 


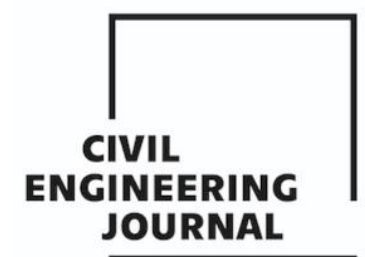

Article no. 35

THE CIVIL ENGINEERING JOURNAL 2-2021

the pier. Under the action of lateral earthquake, the lateral restraint of the side pier limits the lateral displacement of the structure to a certain extent. Together with the bottom restraint of the middle pier, it limits the lateral bending moment of the bridge, thus reducing the lateral bending moment response of the middle pier section, which is transformed into lateral bending moment of the side pier. The maximum bending moment at the pier bottom section of Model 2 is $26932 \mathrm{kN} \cdot \mathrm{m}$, which reduces the seismic response by $18.4 \%$; the maximum axial force of the pier bottom section 6432 $\mathrm{kN}$ is reduced by $29.3 \%$; the maximum bending moment at the pier top is $20553 \mathrm{kN} \cdot \mathrm{m}$, which is reduced by $27.7 \%$; The maximum axial force of the pier top is $6429 \mathrm{kN}$, which is reduced by $33.7 \%$; the maximum bending moment value of the main beam is $18621 \mathrm{kN} \cdot \mathrm{m}$, which is reduced by $46 \%$. The side pier greatly reduces the bending moment response of the main girder and the vertical seismic response of the middle pier through the vertical restraint, which is transformed into the vertical axial force of the side pier itself. In the longitudinal direction, the middle pier is mainly used to resist external forces, and the restraining capacity of the side piers is limited. Therefore, under a longitudinal earthquake, the effect of the bending moment on the top and bottom sections of the middle pier is basically the same. Through the above analysis, the seismic response of the bridge under the maximum cantilever state is the core of the seismic calculation of the rotating structure: in addition to the calculation of the main girder and pier structure, the force state of the spherical hinge and the footing structure should also be analyzed, for example, observing whether spherical hinge and the footing structure would reach the state of ultimate bearing capacity and whether the structure will undergo lateral instability.

This paper adopts the finite element calculation method, takes the maximum cantilever state as the research object, and selects real seismic waves as the external excitation for time history analysis. The calculation results are close to the real engineering situation. The time history analysis process has a large number of iterations, the total number exceeding 900,000 times, and the calculation time exceeds 3 days, which will bring more time costs to actual projects. Aiming at the characteristics of the swivel system, this paper proposes an optimization algorithm for seismic response, which shortens the calculation time of time history analysis on the premise of obtaining a certain calculation accuracy.

\section{Optimization algorithm for seismic response of continuous rigid frame bridge UHPC spherical hinge swivel system}

\section{Proposal of optimization algorithm}

According to the vibration equation below:

$$
[M]\left\{x^{\prime \prime}(t)\right\}+[C]\left\{x^{\prime}(t)\right\}+[k]\{x(t)\}=-[M]\{I\} x^{\prime \prime}(t)
$$

$[M]$ : mass matrix; $[C]$ : damping matrix; $[k]$ : stiffness matrix; $x(t)$ : displacement function of the structure. The first and second derivatives respectively represent the speed and acceleration functions of the structure. The mode number of the structural system is $n$, and the mode matrix can be expressed as:

$$
[A]=\left[\{x\}_{1}\{x\}_{2} \ldots\{x\}_{n}\right]
$$

The displacement matrix expression is $\{x(t)\}=\left[\{x\}_{1} q_{1}(t)+\{x\}_{2} q_{2}(t)+\cdots+\{x\}_{n} q_{n}(t)\right]=$ $[A]\{q\}$. Combine the displacement matrix with equation (5), the following formula is obtained:

$$
M_{j}^{*} q_{j}^{\prime \prime}+C_{j}^{*} q_{j}^{\prime}+k_{j}^{*} q_{j}=-\{X\}_{j}^{T}[M]\{I\} x^{\prime \prime}(t)
$$

$M_{j}^{*}=\{X\}_{j}^{T}[M]\{X\}_{j}^{T}, \quad C_{j}^{*}=\{X\}_{j}^{T}[C]\{X\}_{j}^{T}, \quad K_{j}^{*}=\{X\}_{j}^{T}[k]\{X\}_{j}^{T}$, after transformation, equation (7) can also be presented as the following equation: 


$$
q_{j}^{\prime \prime}+2 \zeta_{j} \omega_{j} q_{j}^{\prime}+\omega_{j}^{2} q_{j}=-\gamma_{j} x^{\prime \prime}(t)
$$

$\gamma_{j}$ is the mode shape participation coefficient, its expression shown as follows:

$$
\gamma_{j}=\frac{\{X\}_{j}^{T}[M]\{I\}}{\{X\}_{j}^{T}[M]\{X\}_{j}}=\frac{\sum_{i=1}^{n} m_{i} x_{j i}}{\sum_{i=1}^{n} m_{i} x_{j i}{ }^{2}}
$$

The mass point $i$ is subjected to the unit mass $x_{0}^{\prime \prime}(t)$, and is assigned by $\gamma_{j}$ to the mode $j$; then the following equation is obtained:

$$
q_{j}(t)=-\frac{\gamma_{j}}{w_{j}} \int_{0}^{t} e^{-\rho_{J} w_{j}(t-\tau)} x_{0}^{\prime \prime}(\tau) \sin w_{j}(t-\tau) d \tau=\Delta_{j}(t) \gamma_{j}
$$

From the above formula, the displacement of the $j$-th mode shape is $x_{j i} \Delta_{j}(t) \gamma_{j}$. The expressions for all mode shape displacement and acceleration are:

$$
x_{i}(t)=\sum_{j=1}^{n} \gamma_{j} \Delta_{j}(t) \gamma_{j}, x_{i}^{\prime \prime}(t)=\sum_{j=1}^{n} \gamma_{j} \Delta_{j}{ }^{\prime \prime}(t) \gamma_{j}
$$

From the above formula, the expression of the inertial force at the mass point $i$ in the structure is as the following:

$$
F_{i}(t)=m_{i}\left[x_{i}^{\prime \prime}(t)+x_{0}{ }^{\prime \prime}(t)\right]
$$

According to the structure kinematics equation, the inertial force on the mass poin $i$ is:

$$
F_{j i}(t)=m_{i}\left[\gamma_{j} \Delta_{j}^{\prime \prime}(t) x_{j i}(t)+\gamma_{j} x_{j i} x_{0}{ }^{\prime \prime}(t)\right]
$$

Then the maximum inertial force is:

$$
F_{(j i) \max }=m_{i} \gamma_{j} x_{j i}\left|\left[\Delta_{j}{ }^{\prime \prime}(t)+x_{0}{ }^{\prime \prime}(t)\right]\right|
$$

$\Delta_{j}{ }^{\prime \prime}(t)$ is the seismic acceleration under the initial acceleration state $x_{0}{ }^{\prime \prime}(t)$. The equation $\|\left[\Delta_{j}{ }^{\prime \prime}(t)+x_{0}{ }^{\prime \prime}(t)\right] \mid$ can be obtained from the response spectrum according to the seismic fortification intensity and the characteristic period of the site. The above formula thus can be rewritten as the following:

$$
F_{j i}=\gamma_{j} x_{j i} \alpha_{j} G_{i}
$$

$\alpha_{j}$ is the horizontal seismic influence coefficient of mode $j ; x_{j i}$ is the horizontal relative displacement of mode $j$ at the mass point $i, \gamma_{j}$ the participation coefficient of mode $j$. According to the SRSS method, the total effect expression of seismic action is as follows:

$$
S=\sqrt{\sum S_{j}^{2}}
$$

\section{Examples}

The basic seismic acceleration of the translational system is $0.1 \mathrm{~g}$; the characteristic period of the site is $0.45 \mathrm{~s}$, and the damping ratio of the structure is 0.05 . The thrust stiffness of the pier is $\mathrm{k}_{1}=\mathrm{k}_{2}=3 \mathrm{El} / \mathrm{H}$, where $\mathrm{E}$ is the elastic modulus of the pier and $\mathrm{I}$ is the transverse bending moment of inertia of the pier; $\mathrm{H}$ is the height between the pier foundation and the main beam. The movement of the rotating structure can be equivalent to the movement of the elastic body with two degrees of freedom. Mass point 1 is the position of the centroid of the pier, and the mass is the mass of the pier itself, $m_{1}=686 \mathrm{t}$. Mass point 2 is the position of the top of the pier, and the mass is the total mass of the main beam of the superstructure and the bridge paving load, $m_{2}=9000 t$. According to the kinematic equations: 


$$
\left(\left[\begin{array}{ll}
k_{11} & k_{12} \\
k_{21} & k_{22}
\end{array}\right]-\omega^{2}\left[\begin{array}{cc}
m_{1} & 0 \\
0 & m_{2}
\end{array}\right]\right)\left(\begin{array}{l}
x_{1} \\
x_{2}
\end{array}\right)=\left(\begin{array}{l}
0 \\
0
\end{array}\right)
$$
follows:

The stiffness matrix is $\mathrm{k}_{11}=\mathrm{k}_{1}+\mathrm{k}_{2}, \mathrm{k}_{12}=\mathrm{k}_{21}=-\mathrm{k}_{2}, \mathrm{k}_{22}=\mathrm{k}_{2}$. The formula can be transformed as

$$
\begin{aligned}
& \qquad\left|\left[\begin{array}{ll}
k_{11} & k_{12} \\
k_{21} & k_{22}
\end{array}\right]-\omega^{2}\left[\begin{array}{cc}
m_{1} & 0 \\
0 & m_{2}
\end{array}\right]\right|=0 \\
& \text { Combined calculation of determinant: }\left|\left[\begin{array}{cc}
k_{11}-\omega^{2} m_{1} & k_{12} \\
k_{21} & k_{22}-\omega^{2} m_{2}
\end{array}\right]\right|=0
\end{aligned}
$$

The angular frequency can be obtained from the above formula, and the mode diagrams at different natural frequencies can be obtained by continuing to solve the displacement matrix. By calculating the first few modes of the structure, the lateral main mode of the pier is drawn and solved. Through the previous finite element analysis, the first mode and the seventh mode in Model 1 are respectively the first and second lateral bending modes of the pier. The calculation results of the modal are directly used in the calculation. The frequency of the 7th mode is $4.06 \mathrm{~Hz}$ with a period of $0.246 \mathrm{~s}$, and the frequency of the first mode is $4.06 \mathrm{~Hz}$ with a period of $2.564 \mathrm{~s}$. Take the 7th mode in the finite element model as the first mode of calculation, i.e., $T_{1}=0.246 \mathrm{~s}$. The first mode is used as the second mode of calculation, $T_{2}=2.564 \mathrm{~s}$. The mode displacement is shown in Figure 14 . The natural vibration displacement is normalized, and the natural vibration law of the elastic body with two degrees of freedom is obtained.

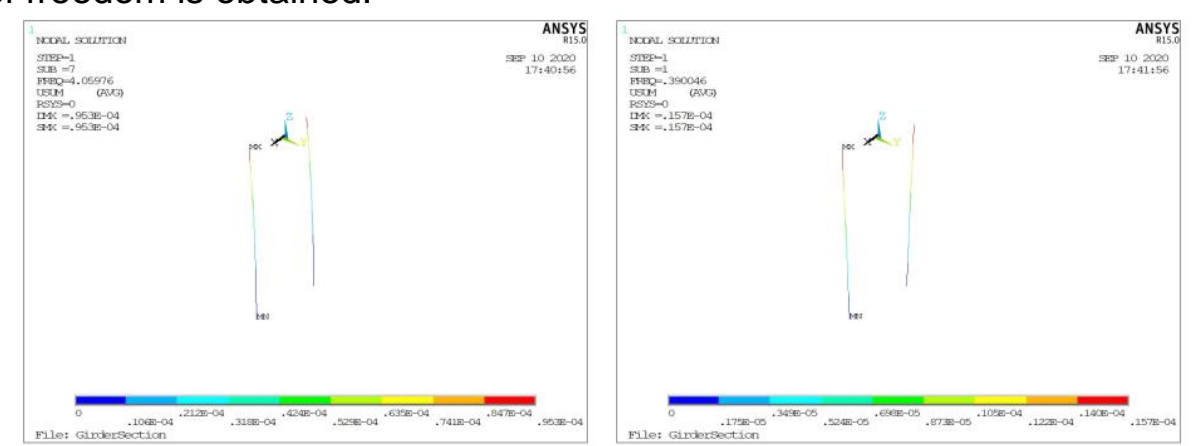

Fig. 14 - First and second order transverse bending modes of bridge piers

The response of the first mode under horizontal seismic action will be discussed here. According to the design response spectrum, the seismic acceleration is $0.1 \mathrm{~g}$, and the influence coefficient of a horizontal earthquake is $\alpha \max =0.08$. Since $\mathrm{Tg}=0.45 \mathrm{~s}$, and $0.1<\mathrm{T} 1<\mathrm{Tg}$, then $\alpha 1=\alpha \max =0.08$, which can be obtained from equation (9):

$$
\gamma_{1}=\frac{\sum_{i=1}^{n} m_{i} x_{j i}}{\sum_{i=1}^{n} m_{i} x_{j i}{ }^{2}}=\frac{1.0 \times 686+2.1 \times 9000}{1.0^{2} \times 686+2.1^{2} \times 9000}=0.485
$$

Combine it with equation (12), the horizontal seismic force on two mass points is obtained:

$$
\begin{gathered}
F_{11}=\gamma_{1} x_{11} \alpha_{1} G_{1}=0.485 \times 1.0 \times 0.08 \times 686 \times 10=266.2 \mathrm{kN} \\
F_{12}=\gamma_{1} x_{12} \alpha_{1} G_{2}=0.485 \times 2.1 \times 0.08 \times 9000 \times 10=7333 \mathrm{kN}
\end{gathered}
$$

Similarly, the horizontal seismic action of the second-order mode is T2>5Tg, according to the design response spectrum, $\alpha_{2}=0.037$, then

$$
\gamma_{2}=\frac{\sum_{i=1}^{n} m_{i} x_{j i}}{\sum_{i=1}^{n} m_{i} x_{j i}{ }^{2}}=\frac{1.0 \times 686+1.7 \times 9000}{1.0^{2} \times 686+1.7^{2} \times 9000}=0.60
$$

Thus, the horizontal seismic action should be:

$$
\begin{gathered}
F_{21}=\gamma_{1} x_{11} \alpha_{1} G_{1}=0.6 \times 1.0 \times 0.037 \times 686 \times 10=152.3 \mathrm{kN} \\
F_{22}=\gamma_{1} x_{12} \alpha_{1} G_{2}=0.6 \times 1.7 \times 0.037 \times 9000 \times 10=3397 \mathrm{kN}
\end{gathered}
$$

According to the SRSS method, after the two modes are superimposed, $F 1=306 \mathrm{kN}, F 2=8081$ $\mathrm{kN}$, then the bending moment of the pier bottom $M x^{\prime}=306(10-2.9) / 2+8081(10-2.9)=58462 \mathrm{kN} \cdot \mathrm{m}$. The finite element result is $M x=233025=66050 \mathrm{kN} \cdot \mathrm{m}$, and the optimization algorithm is $90 \%$ of the finite element calculation result, which is close to the finite element calculation result. 


\section{CONCLUSIONS}

In this paper, the mechanical behaviour of continuous rigid frame bridge UHPC spherical hinge translation system under seismic action is studied, and the following conclusions are obtained:

(1) Based on the seismic data of the Pacific Earthquake Engineering Research Center (PEER), 18 seismic waves of Model 1 and Model 2 in the three directions are screened to meet the calculation requirements. The calculation results of real seismic waves are highly discrete, but the average value is close to the calculation results of the response spectrum method.

(2) The main seismic response of Model 1 is the lateral bending and vertical axial force at the bottom of the pier, also, the longitudinal and lateral bending of the main girder. The turntable structure bears the internal force of the pier and the UHPC spherical hinge bears all the axial pressure and $20 \%$ of the lateral bending moment, the footing structure bearing the remaining $80 \%$ of the lateral bending moment. As to Model 2, the lateral bending moment and vertical axial force at the bottom of the pier reduce by $18.4 \%$ and $29.3 \%$, respectively, and the maximum bending moment of the main beam at the root of the cantilever reduces by $46 \%$. The side pier bears part of the internal force of the middle pier and the main beam, so the stress analysis during the horizontal rotation is the focus of the bridge seismic analysis.

(3) An optimization algorithm for the seismic response of a continuous rigid frame bridge in the horizontal rotation process is proposed, which has higher accuracy compared with the calculation results of time history analysis and response spectrum method. Post-evaluation of the seismic performance of the bridge has been carried out for the built project. The compressive stress of the footing structure is reduced by increasing the distance between the footing structure and the center of rotation, increasing the number of the footing structure, increasing the wall thickness of the footing structure, and adopting a steel tube concrete structure. Thereby improving the seismic performance of the bridge horizontal swivel system.

\section{AFFILIATION}

Supported by “The Initial Scientific Research Funds of Anhui polytechnic University”, and the project number is $2021 \mathrm{YQQ} 021$

\section{REFERENCES}

[1] Deng Renbin, Tang Weijun. Current situation and development prospect of highway and bridge construction in China [J]. Heilongjiang transportation science and technology, 2017, 40 (07): $139+141$.

[2] J. Zhang, T. E. El-Diraby, Constructability analysis of the bridge superstructure rotation construction method in China [J]. 132(2006),353-360.

[3] Siwowski, Tomasz, Wysocki, Artur, Horizontal rotation via floatation as an accelerated bridge construction for long-span footbridge erection: Case study[J]. Journal of Bridge Engineering,20(2015),124126.

[4] Wu Yuyong. Key points of construction technology for transit bridge in bridge engineering [J]. Highway transportation technology (Application Technology Edition), 2019, 15 (08): 105-107.

[5] Liu Haiqi, Overview of main bridge swivel system of dulaying Bridge[J]. Transportation world, 03(2016):80-81.

[6] Wang Shuwang, Design of curved swivel T-shaped rigid frame for Beijing Shanghai Railway[J]. Railway Construction Technology, S2(2010):24-26+52.

[7] Lu Jinhua, Study on construction control and stability of large tonnage continuous rigid frame bridge[D]. Lanzhou Jiaotong University, 2016.

[8] Wei Qing, Research on the construction technology of super wide asymmetric T-frame swivel over Zheng Wan high speed railway[J]. Railway Construction Technology, 04(2020):69-72.

[9] Wang, Jiawei; Sun, Quansheng. Experimental Study on Improving the Compressive Strength of UHPC Turntable. Advances in Materials Science and Engineering [J], Vol.2020, WOS: 000556811300003.

[10] Wang, Jiawei; Sun, Quansheng. Dynamic analysis of swivel construction method under multi-variable coupling effects. International Journal of Structural Integrity[J], 2019, Vol.10, No.4, pp:580-598. Accession number:20192507063782. 
[11] Wang, Jiawei; Sun, Quansheng. Experimental research on compressive strength of UHPC spherical hinge. International Journal of Structural Integrity [J], 2019, Vol.10, No.6, pp: 518-537. Accession number: 20194607674167.

[12] Wang, Jiawei; Sun, Quansheng. Parameter sensitivity analysis of stability of T-shaped rigid frame bridge by adopting swivel construction method. Multidiscipline Modeling in Materials and Structures [J], 2020. Accession number: 20201808588847.

[13] Wang Changjie. Integral stress analysis and pier optimization design of T-shaped rigid frame bridge with Swivel Construction[D]. Southwest Jiaotong University, 2017.

[14] Wang Xinmin. Numerical analysis of ANSYS engineering structure[M]. Bei Jing: People's Communications Press, 2020.

[15] National standards of the people Republic of China. Code for seismic design of buildings (GB 500112010) [S]. China Construction Industry Press, 2016.

[16] National standards of the people's Republic of China. Detailed rules for earthquake resistance of Highway Bridges (GBT50152-2012) [S]. People's Communications Press, 2012. 